\title{
Wilson Cano, um intelectual exemplar
}

\section{Wilson Cano, an exemplary intellectual}

\author{
Fernando Macedo e Beatriz Mioto*
}

Resumo: Este artigo resgata a trajetória e algumas contribuições do economista Wilson Cano (1937-2020) para o pensamento social brasileiro. Além de apresentar um quadro geral de sua obra, o texto destaca a trajetória de vida do homenageado em três momentos: um breve histórico de suas origens e juventude; atuação profissional anterior à Unicamp (instituição em que passou a maior parte da vida); e contribuições para ensino, pesquisa e docência a partir dessa instituição. $\mathrm{O}$ artigo destaca algumas reflexões do autor para compreensão do subdesenvolvimento em diversas escalas, especialmente no que tange à dinâmica regional e urbana brasileira, área em que se notabilizou como um dos mais importantes intérpretes do Brasil.

Palavras-chave: Wilson Cano. Economia. Desenvolvimento econômico. Economia regional e urbana.

\begin{abstract}
This article addresses the trajectory and some contributions of the economist Wilson Cano (1937-2020) to Brazilian social thought. In addition to presenting a general picture of his work, the text highlights the life trajectory of the honoree in three moments: a brief history of his origins and youth; professional activity prior to Unicamp (institution where he spent most of his life); and his contributions to teaching and research from this institution. The article highlights some reflections by the author to understand underdevelopment at various scales, especially with regard to the Brazilian regional and urban dynamics, an area in which he became renowned as one of the most important interpreters in Brazil.
\end{abstract}

Keywords: Wilson Cano. Economy. Economic development. Regional and urban economics.

JEL: B31; O54; R00

\footnotetext{
* Respectivamente: (1) Professor do Instituto de Economia da Unicamp, pesquisador do Centro de Estudos do Desenvolvimento Econômico - CEDE e coordenador do Grupo de Estudos das Transformações Econômicas e Territoriais - GETETE | E-mail: fcmacedo@unicmp.br | ORCID: 0000-0002-8690-2077 | (2) Professora do Centro de Engenharia, Modelagem e Ciências Sociais Aplicadas da Universidade Federal do ABC | E-mail: bea.mioto@gmail.com | ORCID: 0000-0001-7339-4192
} 


\section{Apresentação}

No dia 3 de abril de 2020, o Brasil perdeu um de seus mais importantes intérpretes, o professor Wilson Cano. Economista, Wilson deixou uma obra composta por mais de uma centena de artigos e oito livros de autoria individual. Pesquisador Emérito do CNPq, sua produção acadêmica apresenta diversidade temática que passa por investigações sobre o Brasil e a América Latina relacionadas às áreas de Desenvolvimento Econômico, Desenvolvimento Regional e Urbano, História Econômica, Política e Planejamento Econômico, Economia Internacional e Setor Público, além de análises de conjuntura que indicavam sua urgência republicana de participação no debate sobre os grandes temas do país. Nos últimos anos, dedicou-se ao estudo da política econômica e da desindustrialização brasileiras após 1990. Foi, inclusive, um dos primeiros a anunciar a derrocada da indústria no país muito antes de o tema entrar na pauta de discussão de estudiosos. No entanto, diferente da maioria dos que viriam a tratar a questão, apontava a raiz do problema no esgotamento do modelo de desenvolvimento econômico e industrial brasileiro manifestado na crise dos anos 1980 e não a partir da segunda metade dos 1990 e, especialmente, do início do século XXI, como comumente se observa no debate.

Wilson foi um intelectual genuinamente brasileiro, herdeiro da tradição latino-americana, que tem na Cepal de Raul Prebisch e na contribuição teórica de Celso Furtado as raízes de uma fecunda interpretação sobre a problemática do subdesenvolvimento dependente de nosso continente. Seu livro Política econômica e soberania da América Latina apresenta o quadro da região nos anos 1990 e atesta sua preocupação com "Nuestra America" nos marcos do movimento mais geral da economia globalizada na ordem neoliberal. Avançava no esforço que realizou sete anos antes na obra Reflexões sobre o Brasil e a (des) Ordem Internacional, na qual buscava entender os impactos das transformações da economia internacional sobre o Brasil e seus efeitos tanto na estrutura produtiva quanto na política econômica, em contexto de crescente neoliberalização e enfraquecimento do Estado nacional. As obras derivaram de pesquisas no exterior, quando realizou dezenas de entrevistas em dois momentos distintos da década de 1990. Os livros trazem uma marca presente em toda produção do autor: conhecer in loco a realidade a ser estudada e fazer estudos comparativos que permitam entender e atuar sobre a realidade do país (e da região), a partir da compreensão dos constrangimentos externos. 
Seu posicionamento político e sua interpretação sobre o Brasil não deixavam dúvidas sobre em qual lado estava na luta pela soberania do país, pelo projeto nacional de desenvolvimento através do esforço de industrialização, que defendeu até o fim da vida, e pela justiça social. Lembrava aos mais jovens que essas questões estavam colocadas permanentemente em nossa agenda socioeconômica e que era preciso engajamento coletivo para superação do subdesenvolvimento e da dependência externa, sem o que não seria possível avançar na construção da Nação.

Por meio do método histórico-estrutural de pesquisa, Wilson desceu as escalas espaciais para estudar as estruturas econômicas das regiões brasileiras, tornando-se o mais reconhecido pesquisador nessa área. Sua obra fornece abrangente quadro da dinâmica regional do país ao fazer a interpretação, em retrospectiva histórica de longa duração, da gênese das desigualdades regionais - e de como estas se vinculam à formação e integração do mercado interno - até a evolução e transformação da estrutura espacial de uma economia nacional regionalmente localizada. Desemboca nos dias de hoje, ao tratar da desconcentração produtiva regional e dos efeitos da desindustrialização na dinâmica urbano-regional do Brasil. Professor compromissado com a transformação, legou - há uma década - agenda para os estudos regionais e urbanos que se mantém atual ${ }^{1}$ e que baliza um conjunto de estudos que estão sendo realizados hoje na área por estudantes, professores e pesquisadores que ele formou.

Outros quatro livros publicados em coautoria - que juntos totalizaram catorze volumes - derivaram das pesquisas que coordenou sobre a socioeconomia de São Paulo e da região metropolitana de Campinas. Neles, atualiza as análises que se iniciaram em sua obra mais reconhecida academicamente Raízes da concentração industrial em São Paulo -, na qual demonstrou por que o núcleo dinâmico da economia brasileira localizou-se na capital paulista, iniciada a diversificação produtiva em direção à indústria, a partir dos desdobramentos do complexo cafeeiro de São Paulo.

Pela força das análises apresentadas no livro - que foi resultado de sua tese doutoral -, tornou-se referência na interpretação e nos estudos sobre a dinâmica regional e leitura obrigatória para o entendimento de nossos desequilíbrios regionais, especialmente após a publicação, em 1981, de sua tese de livre-docência, Desequilíbrios regionais e concentração industrial no Brasil (1930-

\footnotetext{
${ }^{1}$ Ver Cano (2011).
} 
1970). A análise sobre o complexo cafeeiro paulista, o complexo nordestino, a economia amazônica da borracha, a economia do extremo sul e, posteriormente, com as outras economias cafeeiras, ${ }^{2}$ avança na interpretação de Furtado ([1958] 1980) sobre a formação regional brasileira.

No estudo regional comparativo, Cano ([1977] 1991,1985) demonstrou por que a cafeicultura paulista, a partir da segunda metade do século XIX, conseguiu gestar uma rede urbana mais articulada e promover um processo de diversificação industrial graças: (1) à capacidade maior de retenção de seu excedente; (2) à divisão social do trabalho mais avançada que se refletiu numa separação campo-cidade que não se verificou nas outras regiões que passaram por ciclos agroexportadores, para qual cumpriu papel fundamental a agricultura produtora de alimentos em São Paulo; (3) à estrutura de propriedade rural que não era tão concentrada como no Nordeste, tampouco fragmentada como no Espírito Santo e em parte do Sul do país; e, finalmente, (4) ao avanço das relações assalariadas. ${ }^{3}$ Numa abordagem histórica,Wilson analisou as estruturas socioeconômicas e os processos que engendraram diferentes arranjos regionais que seriam decisivos no posicionamento de cada região após a integração do mercado nacional por meio da industrialização comandada a partir de São Paulo.

O método presente em sua tese de doutoramento foi replicado para um conjunto de estudos territoriais através de seus discípulos espalhados por todo o país, o que possibilitou conhecimento mais acurado de nossas diversidade e heterogeneidade regionais e urbanas. Entre dissertações e teses, foram mais de sessenta orientações realizadas diretamente por ele, sem contar a influência indireta através de seus ex-alunos.

É impossível em um texto desta natureza tratar da trajetória e da contribuição intelectuais deste autor com a profundidade que ele merece. Abordaremos alguns pontos sem qualquer pretensão de esgotá-los; antes, porém, contemos um pouco da trajetória de Wilson Cano, anterior à sua atuação como professor da Universidade Estadual de Campinas (Unicamp), instituição na qual ele ingressou desde o início de seu funcionamento e à que se dedicou até o fim de sua vida, sem jamais abandonar a sala de aula, mesmo após sua aposentadoria compulsória em dezembro de 2007.

\footnotetext{
${ }^{2}$ Sobre a comparação entre as economias cafeeiras, ver Cano (1985).

${ }^{3}$ Conforme mencionado em Macedo (2010).
} 


\section{A origem familiar em um estado em transformação ${ }^{4}$}

É sempre curioso visitar a trajetória de vida das pessoas que admiramos. Parece que, quando temos oportunidade de conhecê-las, o que entendíamos como extraordinário é, em parte, apenas ignorância sobre como a vida encontra seu sentido. Embora a obra de Wilson Cano seja vasta, ele não deixou entre seus escritos textos autobiográficos, especialmente uma sistematização de sua vida anterior às experiências profissionais como economista. Florestan Fernandes, por exemplo, quando analisa sua trajetória nas Ciências Sociais, diz, de forma emocionante, que as questões que perpassaram suas preocupações acadêmicas tinham origem no confronto entre a realidade da pobreza e dos cortiços, onde vivia, e os lugares que frequentava na itinerância do subemprego que ocupava sua mãe. Wilson nunca fez um paralelo claro como esse, mas, ao conhecermos com mais detalhes a sua história, é possível colocá-lo entre os intelectuais orgânicos da classe trabalhadora do país. Nisso reside não apenas o rol de questões que ele se propôs a formular e debater para pensar um projeto de desenvolvimento e justiça social para o país, mas também a integridade com a qual cumpriu o oficio de professor.

Como a maior parte dos imigrantes europeus que aportaram no país na primeira década do século XX, Maria Ramos e Rafael Cano, pais de Wilson, vieram, ainda adolescentes, para trabalhar na lavoura de café. Oriundos da região de Málaga/Andaluzia, sendo sua mãe do pequeno município denominado Estepona, colocaram-se em movimento em um período em que a imigração espanhola, como destaca Martinez (1999), dava-se a partir dos ganchos. Estes eram uma espécie de "intermediadores" que encontravam "lavradores pobres de míseras e desafortunadas regiões da Espanha ou em que a organização da propriedade ou do trabalho lhes era mais adversa:Almería, Jaen, Granada, Málaga” (Martinez, 1999, p. 245). Tais agentes ofereciam condições de imigração "favoráveis" para São Paulo (passagem gratuita, albergues etc.), e, por essa razão, o estado tornou-se o maior destino de imigrantes espanhóis no país. Segundo a mesma autora, entre 1910 - ano da chegada da família Cano ao porto de Santos e da fundação do Sport Club Corinthians Paulista - e 1914, foi registrada a entrada de 108.154 espanhóis, na sua maioria Galegos e Andaluzes pobres cuja situação de migrante condicionava o

\footnotetext{
${ }^{4}$ Os autores agradecem à família Cano, especialmente ao filho de Wilson, Newton Cano, por sanar dúvidas e compartilhar informações sobre a trajetória de vida do nosso homenageado.

${ }^{5}$ Não seria razoável escrever um artigo dessa natureza e não mencionar o time do coração do nosso homenageado. Sua dedicação ao time era proporcional à dedicação a suas atividades profissionais.
} 
destino possível, onde os incentivos não demandavam recursos prévios. Enquanto os primeiros dirigiram-se majoritariamente às áreas urbanas, os segundos inseriram-se a partir do meio rural.

O destino das famílias Ramos e Cano foi o município de Descalvado, distante cerca de $40 \mathrm{Km}$ de São Carlos e $240 \mathrm{Km}$ da capital do estado. Naquele município onde viveram até o final da década de 1920, Maria e Rafael se casaram em 1916. Essa região, que será objeto de estudo de Wilson, havia sido uma das zonas de agricultura mais desenvolvidas do estado no final do século XIX e início do século XX. Nos quase vinte anos que passou no interior, a família Cano logrou tornar-se proprietária e produtora de café. Segundo Martinez (1999), no mundo rural foi comum essa trajetória, tendo a maioria dos espanhóis se dedicado à produção agrícola (café, cebola, laranja etc.) e, em alguns casos, ao comércio. $\mathrm{O}$ acesso à terra se dava a partir do trabalho familiar nas lavouras ou, em menor medida, pelo financiamento da compra de terras para aquelas famílias que já vinham com algum recurso. No entanto, conforme Faleiros (2007), no final da década de 1910 a região já passava por um processo de decadência e/ou estagnação das lavouras, com queda de produtividade.

Em que pese os problemas da produção cafeeira - que ensejariam as políticas estatais de proteção do café que posteriormente Wilson viria a estudar -, a família permaneceu vivendo da propriedade e atividade rural e prosperando. O pai de Wilson se tornou administrador de duas fazendas e a família vivia em boas condições, inclusive adquirindo propriedades rurais.Tal realidade se transforma com a crise de 1929, quando, em função da conjuntura econômica e de imperativos familiares, vendem suas terras e se deslocam para a cidade de São Paulo. A ida para a capital foi reforçada pelo sonho da família em ter uma vida urbana. Seu pai, Rafael, começa a trabalhar no comércio e depois abre uma carvoaria, mas a trajetória de empresário será limitada pelo jogo e pelo alcoolismo, o que comprometerá, da mesma forma, a vida familiar.

Ao contrário das décadas anteriores quando a imigração internacional dava a tônica da dinâmica populacional de São Paulo, nesse momento as migrações internas passam a explicar o rápido processo de urbanização que avançava com o aprofundamento da industrialização. No livro $A$ cidade de São Paulo: estudos de geografia urbana, Aroldo de Azevedo nos brinda com uma compilação de relatos de personalidades e viajantes sobre a cidade. Em torno de 1935, Ullmann (apud Azevedo, 1958, p. 142), por exemplo, escreve que 
Essa cidade que faz lembrar toda espécie de cidades e, no entanto, não se parece com nenhuma. Talvez nessa "“'Chicago sul-americana" já exteriormente se manifeste que entre o milhão de habitantes que ela conta estão representados todos os povos da Europa e ainda alguns da Ásia. Ao lado de arranha-céus inacabados, cujas rendas futuras estão em discussão, ao lado de maravilhosas avenidas com grandes palacetes, um bairro comercial apertado e quase asfixiado pelo trânsito e subúrbios que lembram quarteirões proletários em qualquer lugar do Mediterrâneo.

Pierre Deffonteines, por sua vez, diz que "São Paulo pertence, por excelência, à família das cidades de energia" (Deffonteines apud Azevedo, 1958, p. 142). Portanto, a expansão cafeeira, as origens da industrialização em São Paulo e a urbanização, que serão brilhantemente exploradas na obra de Wilson, já estavam, por assim dizer, em seu DNA.

Em contraste com a pujança da "cidade de energia", a família Cano chega em São Paulo no início dos anos 1930 estabelecendo-se no que, ao tempo, constituía-se a periferia da cidade "para além" da margem direita do Rio Tietê, dos bairros Santana, Tucuruvi e Parada Inglesa. Essa região da cidade, até meados da década de 1920, era uma área eminentemente rural relacionada aos caminhos no sentido da Cantareira (e sua estrada de ferro), sem luz elétrica, saneamento etc. A geógrafa Odette Seabra, em seu livro Os Meandros dos rios os meandros do poder, descreve da seguinte maneira a região:

Ainda no começo do século, os processos da cidade começariam a aparecer nas áreas de além-Tietê, apesar das incomensuráveis dificuldades de comunicação existentes entre as duas margens do rio. [...] Por elas [as pequenas trilhas] circulava uma população de fora, recém-chegada, destinada a formar o contingente de pobres que começou a se estabelecer em meio a áreas semirrurais e mesmo rurais de além-Tietê, para se constituir em trabalhadores daquelas e possivelmente outras indústrias [referindo-se especificamente a uma fábrica de cordas]. (Seabra, 2019, p. 43)

A transformação da zona norte da cidade para além do rio se dá com o avanço paulatino das obras de retificação do Tietê, que se iniciam com os planos/projetos no final dos anos 1920, desenvolvem-se, concretamente, a partir de 1937 e perduram século XX adentro. Além de reduzir as áreas de inundação e conectar espacialmente a região à cidade propriamente dita, a retificação também transforma a terra "rural" em terra urbana, promovendo amplo processo de especulação imobiliária. Além da urbanização, esse é um 
dos aspectos mais marcantes da interpretação de Wilson no âmbito urbano, que estabelece o papel do capital mercantil na dinâmica das cidades, conforme ele demonstrou em diversos trabalhos e como ele fora percebendo em seu cotidiano numa cidade em transformação e nos relatos da experiência familiar no meio rural em Descalvado.

Em 1937 também ocorre outro evento importante: o nascimento de Wilson Cano, em 11 de dezembro. Ele é o caçula de oito irmãos (dos quais três morrem antes de seu nascimento de enfermidades típicas do início do século, como sarampo) e será o único a avançar na educação formal, sob forte influência de sua irmã e madrinha chamada Maria, como a mãe. Com a ausência de seu pai no sustento familiar,Wilson cresce em condições muito dificeis, como muitos brasileiros, sustentado fundamentalmente pelo trabalho da mãe que vai costurar peças de couro para vender na feira. $O$ afastamento de Rafael do cotidiano dos filhos decorre de um longo processo de separação que culmina no divórcio formal dos pais quando Wilson tem 20 anos.

Assim, mesmo vivendo em um bairro periférico, que se transforma com a industrialização e o espraiamento da cidade, ele terá a oportunidade de usufruir dos avanços trazidos pela urbanização que, materialmente, sintetiza as mudanças econômicas, sociais, culturais e políticas dos anos 1930, justamente a década tão dedicadamente analisada por ele em sua obra e que fora ponto de inflexão no desenvolvimento industrial do país.

Entre as inúmeras mudanças relevantes desse momento, Antônio Cândido (1984) destaca os aspectos culturais do período, que puderam consolidar “inovações, aspirações e pressentimentos" dos anos 1920 em direção a maior unificação do país. O autor destaca, por exemplo, o papel dos avanços da educação pública, da vida artística, dos meios de difusão cultural como o livro e o rádio. Como produto dessas transformações, o próprio Wilson ensinava que "no mundo urbano você tem que reivindicar coisas para você poder viver de uma maneira melhor... reivindicar transporte, casa, água, esgoto, educação, saúde. A urbanização tem esse fator importante de implementar na sociedade transformações no sentido de forçar as pessoas a pensarem" ${ }^{6}$

Wilson reconhece na escola pública e na criação de uma legislação trabalhista elementos decisivos para sua ascensão social e intelectual, sendo esta - juntamente com sua experiência cotidiana de vida na capital paulista - a razão empírica pela qual defendeu o papel do Estado na superação do subde-

\footnotetext{
${ }^{6}$ Fala retirada do documentário Territórios do planejamento, disponível em: <https://www.youtube.com/ watch? $\mathrm{v}=5$ HUULXfRiiE $>$.
} 
senvolvimento e da dependência do país. As razões teóricas ele construiria com sua formação acadêmica de economista com forte influência cepalina.

Em relação aos estudos, ele teve uma trajetória muito bem-sucedida e dizia que foi na escola, em uma realidade em que diversas classes sociais conviviam nos mesmos espaços do ensino público, que tomou consciência da característica mais marcante, em seu juízo, da nossa sociedade: a injustiça social. Não é à toa que, para ele, essa será uma preocupação indissociável da ideia de desenvolvimento. Ou seja, a realidade e o cotidiano vividos influenciaram o que viria a ser sua futura agenda de pesquisa. Em relação à legislação trabalhista, Wilson atribuía a Vargas (não de forma ingênua, obviamente) a melhora das condições materiais de sua família, especificamente de sua irmã/ madrinha e sua mãe. Dessa forma, não surpreende que, em confronto com sua própria história, Wilson tenha sempre destacado a relevância e as contradições da década em que nasceu (e da anterior) ${ }^{7}$ como momento crucial da vida e das possibilidades de construção da nação.

Conjuntamente à sua formação escolar, Wilson começou a trabalhar, aos 15 anos, em um magazine de roupas chamado "Sensação", dedicado a roupas femininas. Conforme pesquisa de Prado (2019), essa rede de lojas fazia parte de um grupo maior de magazines da moda (lojas de departamento) inspirados nas grandes varejistas dos EUA. A Sensação foi criada em 1952 e integrava os vários negócios da família Souza Carvalho, pioneira no ramo e inventora do "crediário" no país. Os donos, oriundos do Ceará, iniciaram os negócios na moda com a importação de modelos de roupas de luxo masculinas e femininas. Especialmente em razão dos constrangimentos econômicos externos, passaram a fabricar parte da produção internamente, a partir da cópia dos modelos franceses e norte-americanos. De certa forma, a Sensação somou-se ao capital imobiliário no que ele entende como as diversas faces do capital mercantil. ${ }^{8}$

Cano começa trabalhando como entregador e, nessa ocasião, alarga seu conhecimento sobre a cidade de São Paulo. Ao circular por diversos bairros em seu trajeto diário entre a casa e o trabalho e entre a loja e as entregas, novamente se confronta com a questão da desigualdade, em um plano ainda mais concreto, mediado pela segregação entre os bairros ricos e pobres, pelo

\footnotetext{
${ }^{7}$ Especificamente sobre a década de 1920, ver Cano $(1997,2012)$. Nos estudos sobre a economia paulista, a década de 1920 era um momento importante destacado porWilson nas periodizações feitas por ele (Cano, 1988).

${ }^{8}$ Uma síntese da interpretação dele sobre o capital mercantil e seu papel constrangedor do desenvolvimento regional está em Cano (2010).
} 
acesso a serviços e paisagens diversas. Ele contou, em ocasiões familiares, que havia entregado produtos para personalidades da época, como a atriz Tônia Carreiro e o cantor Nelson Gonçalves. Nesse sentido, os relatos sobre tal percepção também lembram uma passagem deixada por Florestan que reforça a relação entre o intelectual, o professor, o pesquisador e sua história de vida:

Há pouco interesse em descrever a variedade de ocupações a que precisei dedicar-me ou as venturas e desventuras que pontilharam uma infância e uma adolescência tão marcadas pela necessidade de ganhar a vida, de buscar no trabalho - por vezes humilhante e degradante - um instrumento de relação com os outros e de pressão sublimadora. Fazendo o que me via forçado a fazer também era compelido a uma constante busca para vencer uma condição em que o lumpen-proletário (e não operário) definia os limites ou as fronteiras do que não era gente. Antes de estudar esse processo na pesquisa sobre o negro, vivi-o em todos os matizes e magnitudes. A fronteira que me era negada também era conhecida pela experiência concreta. $\mathrm{Na}$ casa da minha madrinha Herminia Bresser de Lima, onde vivi durante uma parte da infância, ou ocasionalmente ia passar alguns dias; e na casa de outros patrões de minha mãe, entrei em contato com o que era ser gente e viver como gente. (Fernandes, 1994, p. 123-124)

Na Sensação, Wilson fez uma trajetória profissional que o aproximou de muitas questões da economia. Tornou-se, ainda jovem, gerente e teve contato com as operações comerciais e financeiras da firma. Esse contato não era trivial, dado que a Sensação Modas se tornou, já nos anos 1950, uma empresa de capital aberto, numa época em que a presença de grupos familiares era muito forte. Vale mencionar que nela havia uma figura de nome desconhecido, dessas decisivas na vida daqueles que dependem de oportunidades, que seria uma espécie de mentor que incentiva sua carreira na empresa e, especialmente, nos estudos.

\section{A vida acadêmica e os primeiros passos como economista}

Até os 22 anos, Wilson Cano dedicou-se ao "mundo corporativo", quando iniciou também o convívio com o "mundo acadêmico" que se abriu a partir de seus estudos em economia na PUC-SP.Ali, tardiamente em relação a vários intelectuais da sua geração, ele descobre sua inclinação para docência e pesquisa. Sua trajetória na PUC também será destacada e é nesse momento 
que ele passa a organizar, a partir de sua experiência de vida e de seus sólidos valores éticos e morais, uma agenda de pesquisa que estará umbilicalmente atrelada à docência e ao comprometimento político-militante que terá pelo desenvolvimento econômico e social do país.

Esse é um contexto da história intelectual do Brasil em que a questão nacional está no centro do debate. Inspirado por Furtado, Wilson traz essa preocupação em toda a sua obra. É nesse momento também que ele se aproxima da Cepal e constrói metodologicamente a abordagem dos problemas do desenvolvimento em que vai se debruçar a partir de então em diferentes escalas (local, metropolitana, estadual, regional, nacional, internacional).Antes, porém, logo depois de formado, ele trabalhou como economista do Sindicato de Fiação e Tecelagem em Geral do Estado de São Paulo.A guinada profissional veio em 1964, quando participou como aluno do primeiro curso intensivo da Cepal-BNDE, instalado em Belo Horizonte, e se destacou novamente como um dos melhores da turma. Possivelmente por seu bom desempenho, tornou-se economista daquela Comissão, entre 1966 e 1968, além de professor de Elaboração e Avaliação de Projetos dos cursos dessa instituição e do ILPES para o Brasil e exterior, entre 1965 e 1975.

Alguns aspectos centrais na obra de Wilson Cano - sem os quais não seria possível compreender sua atuação docente e sua agenda de pesquisa possivelmente se formaram na segunda metade dos anos sessenta, a partir da experiência no curso da Cepal, e se estruturam na década de setenta, quando ele apresenta as teses de doutorado (1976) e de livre-docência (1980): 1) o entendimento da dinâmica do capitalismo mundial e seu rebatimento nas economias subdesenvolvidas, especialmente na América Latina; 2) o desafio de compreender o capitalismo brasileiro, em suas múltiplas dimensões, com particular ênfase para o desenvolvimento de sua indústria, sem a qual não seria possível superar o subdesenvolvimento; 3) o papel do Estado, a partir do qual deveria orbitar as ações de planejamento em direção a um projeto nacional de desenvolvimento; 4) a análise regional no contexto nacional, com particular destaque para: a) a temática da concentração e desconcentração produtiva, especialmente a industrial; b) as desigualdades regionais; c) a integração do mercado nacional e seu rebatimento sobre as economias regionais; d) o papel do Estado e do planejamento econômico no combate aos desequilíbrios regionais, dentro de um projeto nacional de desenvolvimento.

É bom ressaltar, no entanto, que Wilson sempre foi crítico da transposição, sem as devidas mediações, para a análise regional de teorizações pensadas 
para a análise nacional, como foi o caso da Cepal e de autores heterodoxos dos quais ele era próximo teoricamente, como ele destaca na introdução de Desequilíbrios regionais e concentração industrial no Brasil: 1930-1970 (Cano, 1981). A construção de um método de análise regional, a partir da especificidade da formação histórica do capitalismo brasileiro e das peculiaridades do desenvolvimento e suas forças produtivas, conferiu originalidade ao autor, colocando-o como o principal intérprete do desenvolvimento regional brasileiro no século XX, ao lado de Celso Furtado.

A experiência cepalina foi, portanto, decisiva na trajetória acadêmica não apenas de Wilson, mas também dos pioneiros ${ }^{9}$ que fundaram na Unicamp, em 1968, o Departamento de Planejamento Econômico e Social (Depes), que daria origem ao Instituto de Filosofia e Ciências Humanas (IFCH), do qual ele seria diretor entre 1976 e 1980, e, em 1984, ao Instituto de Economia (IE). Nas palavras do nosso homenageado,

Deve-se a uma circunstância especial a ideia da criação do futuro IE. De um lado, pelos anseios que um grupo de professores da CEPAL, no Rio de Janeiro, manifestava em relação à má qualidade da maioria dos cursos de economia então ministrados no país, pela baixa capacidade crítica que ofereciam para o exame da realidade nacional, pela quase ausência de interdisciplinaridade e pela alienação teórica e política que proporcionavam. Esse grupo alimentou, durante alguns anos, a ideia de criar uma nova Escola de Economia que enfrentasse aquelas deficiências. Ao mesmo tempo, havia outro grupo de intelectuais em São Paulo, que acabava de fazer um Curso de Planejamento Econômico ministrado pela Cepal, e que também alimentava as mesmas preocupações.É nesse momento (1965) que se conhecem e que delineiam as ideias centrais do futuro projeto. O elo dessa união foi, de um lado, o interesse demonstrado por Zeferino Vaz em implantá-lo, como embrião da área de humanidades da UNICAMP, e, de outro, o fato de que o grupo tinha em conta os valores humanos fundamentais e idênticas preocupações políticas. (Cano, 2007, p. 3)

\footnotetext{
9 “O grupo de fundadores era constituído (1967) pelos de São Paulo, Carlos E. N. Gonçalves, Fausto Castilho, João Manuel C. de Mello, Luiz G. M. Belluzzo e Osmar O. Marchese e os que vieram da Cepal, Ferdinando O. Figueiredo, Roberto M. R. Gamboa e Wilson Cano. Pouco depois se incorporava Eolo M. Pagnani (área de empresa), e no início da década de 1970 incorporaram-se outros seniores (Antônio B. Castro, Carlos Lessa, Jorge L. Miglioli e Maria C. Tavares) e, mais à frente, ampliávamos o quadro, com a vinda de Carlos A. Barbosa, Carlos A. Kurkinewa, Frederico Mazzucchelli, José C. Braga, Liana M. L. A. Silva, Luciano G. Coutinho, Paulo A. Baltar e Sérgio Silva." (Cano, 2007, p. 3).
} 
O início do que viria a ser o IE - Unicamp foi um curso de especialização ministrado em 1968, em convênio com a Cepal, com objetivo de "preparar quadros habilitados para o desempenho de funções públicas e privadas e que também introduziam critérios sociais para a avaliação de cada projeto estudado" (Cano, 2007, p. 3-4). Iniciava-se, assim, a trajetória do IE de formação de quadros - para dentro e fora da universidade -, missão na qual Wilson teve particular destaque. Os cursos da Cepal possibilitaram ao professor viajar o Brasil, conhecer sua diversidade regional e incorporá-la à sua agenda de estudos.

Um exemplo de sua autuação, e de como ele projetava na formação de quadros papel fundamental no projeto de país que imaginava - e fez disso uma missão que carregou por toda vida - vem do estado capixaba. Guilherme Henrique Pereira, ex-professor da Universidade Federal do Espírito Santo (UFES), em texto em homenagem a Wilson, em 2017, quando ele foi a Vitória em seu último evento fora de São Paulo, escreveu que o homenageado era um intelectual quase capixaba. Ao citar reconhecidos pesquisadores nacionais forâneos que estudaram o Espírito Santo, mas o fizeram olhando de fora para dentro, Guilherme lembrou que Wilson preferiu criar raízes intelectuais ao formar profissionais para pensar e agir sobre a realidade local.

Essa aproximação aconteceu no final dos anos 1960, quando Wilson cooperou com os cursos da Cepal realizados emVitória. Cursos que formaram, segundo Guilherme, um grupo de profissionais que contribuíram decisivamente para a formulação das políticas de desenvolvimento estadual. Posteriormente, Wilson orientou, direta ou indiretamente, diversos trabalhos (dissertações, tese e pesquisa local) sobre a economia capixaba ${ }^{10}$ que seguiram o caminho teórico e metodológico que ele construiu para estudar a questão regional brasileira, a partir do legado de sua obra de 1977. Esse esforço do professor frutificou em outros estados.

Se cartografássemos a localização dos quadros que Wilson formou, acharíamos o mapa do Brasil quase todo preenchido. Do Amapá, com a tese de doutoramento de Porto (2002) até o Sul do país, ele formou, direta ou indiretamente, gerações de professores e pesquisadores que replicaram seu método de pesquisa que o levou ao reconhecimento do CNPq em 2008,

\footnotetext{
${ }^{10}$ Os trabalhos sobre o espírito Santo que Wilson Cano orientou são de: Ferreira (1986), Buffon (1992) e Mota (2002). Duas dissertações sobre a economia capixaba foram orientadas por ex-orientandos seus que trabalharam com ele: Souza Filho (1990) e Gomes (2008). Destaca-se, ainda, a influência do método de Wilson nos trabalhos Rocha e Cosseti (1983) e Morandi e Rocha (1991), duas das principais referências nos estudos sobre formação econômica do Espírito Santo.
} 
pelo título de Pesquisador Emérito. Um dos poucos economistas a conseguir essa distinção. Quando se fala da influência indireta é porque hoje existem professores espalhados por todo Brasil orientados por docentes ligados diretamente ao seu trabalho de ensino e pesquisa, numa cadeia intergeracional de transmissão do conhecimento. Docentes que replicam seus ensinamentos para as novas gerações.

Portanto, a influência de Wilson é marcante não apenas entre seus orientandos, mas entre aqueles que foram tão somente seus alunos. Goularti Filho (2001), por exemplo, produziu o trabalho sobre formação econômica de Santa Catarina que é hoje, possivelmente, o mais referenciado; base das disciplinas de Economia Catarinense em diversos cursos de Economia do estado. Orientado pelo professor aposentado do IE Jobson Arruda, o trabalho bebe do método de pesquisa e dos ensinamentos de Wilson, que, aliás, prefaciou uma das edições do livro resultante dessa tese.

\section{Rigor metodológico e dedicação à docência}

Poucos professores foram tão dedicados à docência como Wilson Cano. Esse cuidado foi demostrado, fundamentalmente, a partir de duas frentes: a estruturação de cursos (na graduação e na pós-graduação), aulas magistrais (parte delas transcritas ou gravadas pelos alunos ou organizadas em notas de aula publicadas em seu site) e material didático criativo e inovador. Neste último aspecto, fundamentado na ideia de que economistas devem ter ferramentas com sentido prático, Wilson preocupou-se com o alinhamento dos elementos técnicos e metodológicos às especificidades históricas da economia brasileira. Dizia que economistas no subdesenvolvimento precisavam ser criativos, ousados e pouco subservientes às receitas universais. Ou seja, ao formar seus alunos, alertava, em vários prismas, como a solução dos problemas econômicos nacionais necessitava de um entendimento mais amplo do que os manuais de economia e autores oriundos de realidades diferentes ofereciam.

Essa trajetória, que será perseguida em sala de aula até o fim de sua vida, inicia-se em 1970, quando, já na Unicamp, produziu para o primeiro curso de graduação em Ciências Humanas um conjunto de textos que seriam atualizados e dariam origem, quase trinta anos depois, ao seu livro Introdução à Economia: uma abordagem crítica, hoje muito utilizado em vários cursos (de Economia e de outras áreas) em todo país.

Alguns aspectos se destacam nessa obra. Primeiro e mais importante é 
o esforço em oferecer um texto introdutório para estudantes de Economia e áreas afins que resgata e ensina, a partir da contribuição histórico-estrutural, o compromisso com a transformação social do nosso país (e continente). $\mathrm{O}$ professor convida o leitor a uma reflexão sobre a Economia em geral e a do Brasil em particular, e lembra o tempo todo que este é um país subdesenvolvido e não apenas injusto, numa clara contraposição à frase do então presidente da república em 1998, ano de lançamento da obra, que havia dito que o problema do nosso país era a injustiça, posto sermos desenvolvidos. Desse confronto também vinha a crítica certeira aos termos "países emergentes" ou "países em desenvolvimento", dado que, segundo ele, nunca superamos os constrangimentos estruturais do subdesenvolvimento.

Outro aspecto desse livro - de percepção muito dificil para iniciantes, mas facilmente verificável para quem está familiarizado com o método de trabalho do mestre - é que o livro segue uma forma comum dos estudos introdutórios de Economia (economia de mercado, aparelho produtivo, setor externo, setor público, moedas e bancos...), vista na própria estruturação dos capítulos. No desenrolar da obra, no entanto, o professor dá pistas do método de trabalho do pesquisador-economista e dos caminhos para estudar uma dada realidade econômica em diferentes escalas (cidade, região, país...), sempre a observando de dentro. No geral, o autor indica, como sempre faz em seus textos, a grande heterogeneidade das atividades econômicas e dos setores produtivos, das relações humanas e da diversidade de instituições que dão sentido e funcionalidade ao sistema econômico que, em sua concepção, está muito distante da pretensa racionalidade econômica usualmente presente nos livros que percorrem caminho semelhante.

Seu livro se inicia com a primeira grande dimensão de qualquer investigação econômica: a estrutura produtiva. Isto é, a análise da base material - ou das condições objetivas - que determina a forma pela qual os bens e serviços são produzidos, numa certa época por uma dada sociedade. Embora a argumentação recorra à simplificação de processos em situações hipotéticas/ideias, ela é capaz de demonstrar que a análise econômica deve tomar o fio da história como condutor, ou seja, a noção de sistema econômico deve integrar-se à noção de totalidade.

Especificamente no campo dos estudos regionais e urbanos, essa ideia será incessantemente trabalhada por ele e legada aos seus, isto é, defender que a estrutura produtiva de uma região (ou cidade) se integra a um aparelho produtivo nacional e se vincula às suas múltiplas relações internacionais, nas 
quais se dão muitas das determinações da economia regional/local. As múltiplas escalas não podem, portanto, ser tomadas de maneira isolada e, por essa razão, as análises e soluções dos problemas urbanos e regionais não devem prescindir de um diagnóstico global ou de um projeto nacional (escala que, segundo Cano, será determinante para as possibilidades de desenvolvimento). Essa visão também leva a uma crítica ferrenha - e precoce, inclusive se comparado à literatura internacional - aos pressupostos das políticas urbanas e regionais que ascendem nos anos 1980 e 1990 junto ao neoliberalismo, que advogavam a defesa dos localismos como solução para o desenvolvimento regional, com evidente enfraquecimento dos laços federativos, cuja expressão mais evidente no país é a guerra fiscal e suas consequências.

Ao apresentar um olhar para a totalidade sem cair em generalizações, Cano indicava que a formação do economista deveria ter um sentido de aplicação; de outra forma, impossível garantir a transformação social. O subtítulo da obra, "uma contribuição crítica", 11 embora possa incomodar os defensores de uma neutralidade inexistente no processo de ensino-aprendizagem, deixa evidente que ele encarava seu trabalho de docente e pesquisador como uma missão que ia muito além da sala de aula e das publicações que realizou. Aliás, contrapunha-se à cartilha do produtivismo acadêmico. Wilson era refratário a essa imposição de se produzir a qualquer custo e que tem sido aceita acriticamente por parte da nova geração de professores.

Além do compromisso com a formação de economistas, Cano ainda zelou pela formação de pesquisadores, priorizando a pesquisa aplicada. $\mathrm{O}$ conhecimento da realidade por meio dos instrumentos de pesquisa disponíveis e seus limites ficam evidente em sua obra, em especial na trilogia sobre a questão regional brasileira, que explica em profundidade três momentos específicos da dinâmica socioespacial do país: a pré-industrialização e as raízes da concentração industrial em São Paulo; a concentração produtiva em São Paulo e a dinâmica urbano-regional que ela engendrou; e a desconcentração produtiva regional e a complexificação da dinâmica urbano-regional brasileira em contexto de enfraquecimento da indústria e de novas dinâmicas socioeconômicas que surgem fora do core industrial do país. Referimo-nos aos livros já mencionados Raízes da concentração industrial em São Paulo (1977), obra das mais importantes da história econômica brasileira, Desequilíbrios re-

\footnotetext{
${ }^{11}$ Um registro curioso: a capa da segunda edição, por um erro gráfico, saiu sem o subtítulo, o que deixou Wilson furioso, porque ele considerava que essa ausência tirava a força de seus propósitos. Somente quando um dos autores deste artigo mostrou que na parte de dentro o subtítulo aparecia ele ficou mais calmo.
} 
gionais e concentração industrial - 1930-1970 (1981) e Desconcentração produtiva regional no Brasil - 1970-2005 (2008).

Ao fim de cada uma delas, o pesquisador, zeloso com o seu legado, apresenta de forma sistematizada o que já se enxergava diluído ao longo do texto: notas metodológicas explicativas de alguns pontos centrais para o entendimento dos resultados alcançados. Junto a outros trabalhos, essas notas não apenas consolidam seu rigor de pesquisador, mas mostram o profundo conhecimento que tinha sobre as idiossincrasias e fragilidades das grandes pesquisas nacionais que permitem, com lacunas temporais e metodológicas, apreender (ou não) as transformações do país.

Como exemplos adicionais, para ficarmos apenas na área de estudos sobre desenvolvimento regional e urbano, cabe destacar dois textos (e poderiam ser mais) que exemplificam a preocupação com a formação dos alunos e o compromisso com o rigor metodológico de Wilson: 1) "Setor terciário no Brasil:algumas reflexões sobre o período 1970-1989”, escrito com Ulysses Semeghini, no qual aponta a necessidade de enfrentamento de algumas questões metodológicas para o estudo da economia urbana, as quais, em sua maior parte, restringiam a análise, como lembra a professora Maria do Livramento Clementino, ${ }^{12}$ que escreveu uma síntese da obra do mestre, em pequeno texto em sua homenagem de despedida; 2) "Novas determinações sobre as questões regional e urbana após 1980": neste artigo, Wilson não apenas nos deixa como legado uma agenda de pesquisa para os estudos regionais e urbanos no Brasil como escreve uma seção intitulada "Alguns problemas metodológicos", que denuncia descontinuidades e dificuldades para o avanço científico da área. Ou seja, ele apontava tanto o que deveria ser pesquisado quanto os problemas a serem enfrentados, contornados e combatidos pelos pesquisadores.

Um olhar de fora verá apenas (e isso não é pouco) o rigor de um pesquisador. Quem acompanhava seu cotidiano de trabalho conhecia sua preocupação em explicar aos jovens o caminho da pesquisa. Tais preocupações se desdobravam em uma participação intensa na maioria das pesquisas, teses e dissertações do CEDE. Na prática, ele constantemente atentava para o fato de que a crítica no interior de seu grupo de trabalho faria avançar coletivamente os trabalhos individuais. Não à toa foi responsável, em sua história,

\footnotetext{
$12 \mathrm{O}$ texto em homenagem ao professor Wilson Cano, escrito pela professora Maria do Livramento encontra em: <https://1e6b71fa-c892-4e13-ba26-a09d48537b8d.filesusr.com/ugd/13f1ee_27b44e7964a74b44 8ea3e41c9572449d.pdf>. Acesso em: 5 ago. 2020.
} 
por grandes projetos de pesquisa que redundavam em múltiplos trabalhos interligados. Em que pese a dureza das críticas e observações (carinhosamente apelidadas de "bengaladas" por seus alunos), Cano, com a generosidade de poucos, lia os materiais de todos os pós-graduandos que batiam a sua porta e apresentava-lhes os caminhos metodológicos para verificação das teses, hipóteses e, sobretudo, para o alcance dos objetivos propostos. Pacientemente dava valiosas aulas de como fazer pesquisa.

\section{A homenagem em síntese}

Este texto é uma limitada homenagem a um importante intérprete do Brasil, herdeiro e disseminador do pensamento estruturalista cepalino e, também por isso, um estudioso da América Latina. Wilson Cano - mestre de gerações de economistas heterodoxos (e de outros cientistas sociais) - dedicou integralmente mais de cinquenta anos de sua vida ao ensino, à pesquisa e à militância intensa como intelectual por um projeto de país socialmente justo, economicamente industrializado e desenvolvido e soberano na ordem intencional.

Neste momento histórico no qual o país encontra-se desgovernado, sem um projeto nacional capaz de guiá-lo minimamente rumo ao futuro autodeterminado, revisitar a contribuição acadêmica de Wilson Cano é encontrar um campo fértil e criativo de reflexões sobre alternativas para o Brasil que ele sempre pensou e estudou considerando sua diversidade regional, não obstante analisando-o a partir das transformações da economia paulista e sua centralidade para a organização socioespacial do país.

Como professor e pesquisador emérito, Wilson realizou investigações e estimulou seus discípulos a promoverem estudos comparativos dos espaços regionais; para ele, qualquer lugar deste continente Brasil merecia e deveria ser estudado, sempre com fito à construção de um projeto nacional capaz de superar os desequilíbrios regionais e incorporar todos os espaços aos benefícios do desenvolvimento econômico guiado por um Estado Nacional forte e proativo.

\section{Referências}

AZEVEDO, A. A cidade de São Paulo: estudos de geografia urbana. São Paulo: Companhia Editora Nacional, 1958. 
BUFFON, J.A. O café e a urbanização no Espírito Santo: aspectos econômicos e demográficos de uma agricultura familiar. Campinas, 1992. Dissertação (Mestrado em Economia - Universidade Estadual de Campinas).

CANDIDO, A.A Revolução de 1920 e a cultura. Novos Estudos Cebrap. São Paulo, v. 2, n. 4, p. 44-26, abr. 1984.

CANO,W. Padrões diferenciados das principais regiões cafeeiras (1850-1930). Estudos Econômicos, São Paulo, v. 15, n. 2, pp. 291-306, 1985.

CANO,W. Base e superestrutura em São Paulo: 1886-1929. In:DE LORENZO, H. C.; COSTA, W. P. A década de 1920 e as origens do Brasil moderno. São Paulo: Editora Unesp, p. 235-254, 1997.

CANO, W. Da década de 1920 à de 1930: transição rumo à crise e à industrialização no Brasil. EconomiA. Brasília, v. 13, n. 3b, p. 897-916, 2012.

CANO, W. Descontração produtiva regional do Brasil 1970-2005. São Paulo: Unesp, 2008.

CANO, W. Desequilíbrios regionais e concentração industrial no Brasil: 1930-1970. São Paulo: Global/Unicamp, 1981.

CANO, W. Instituto de Economia da Unicamp: notas sobre sua origem e linhas gerais de sua evolução, 2007. Disponível em: <https://1e6b71fa-c892-4e13ba26-a09d48537b8d.filesusr.com/ugd/13f1ee_a32408c6e2a04871852bec9b84d0cfe2.pdf>. Acesso em: 20 dez. 2020.

CANO, W. Novas determinações sobre as questões regional e urbana após 1980. Revista Brasileira de Estudos Urbanos e Regionais. Rio de Janeiro, v. 13, n. 2 , p. 27-52, 2011.

CANO, W. (Org.). O processo de interiorização da indústria paulista - 1920 a 1980. São Paulo: Fundação Seade, 1988. (Coleção Economia Paulista)

CANO, W. (1977). Raízes da concentração industrial em São Paulo. São Paulo: Hucitec, 1991. 
CANO, W. Reflexões sobre o Brasil e a nova (des)ordem internacional. São Paulo: Editora da Unicamp, 1993.

CANO,W. Reflexões sobre o papel do capital mercantil na questão regional e urbana do Brasil. Revista da Sociedade Brasileira de Economia Política. São Paulo, n. 27, p. 29-57, out. 2010.

CANO, W. (Org.). São Paulo no limiar do século XXI. São Paulo: Fundação Seade-Seplan, 1992.

CANO, W. Soberania e política econômica na América Latina. São Paulo: Editora UNESP, 2000.

FALEIROS, R. N. Fronteiras do café: fazendeiros e colonos no interior paulista (1917-1937). Campinas, 2005. Tese (Doutorado em Economia - Universidade Estadual de Campinas).

FERNANDES, F. Ciências Sociais: na ótica do intelectual militante. Estudos Avançados. São Paulo, v. 8, n. 22, p. 123-138, dez. 1994.

FERREIRA, S. P. C. Espírito Santo: dinâmica cafeeira e integração no mercado nacional (1840-1960). Rio de Janeiro, 1986. Dissertação (Mestrado em Economia da Indústria e da Tecnologia - Universidade Federal do Rio de Janeiro).

FURTADO, C. (1958). Formação econômica do Brasil. São Paulo: Editora Nacional, 1980.

GOMES, E. F. C. Desconcentração produtiva regional no Brasil: o caso do Espírito Santo (1990-2005). Campinas, 2008. Dissertação (Mestrado em Desenvolvimento Econômico, Espaço e Meio-Ambiente - Universidade Estadual de Campinas).

GOULARTI FILHO, A. Padrões de crescimento e diferenciação econômica em Santa Catarina. Campinas, 2001. Tese (Doutorado em Economia Aplicada Universidade Estadual de Campinas). 
MACEDO, F. C. Inserção externa e território: impactos do comércio exterior na dinâmica regional e urbana do Brasil (1989-2008). Campinas, 2010. Tese (Livre Docência - Universidade Estadual de Campinas).

MARTÍNEZ, E. E. G. O Brasil como país de destino para os imigrantes espanhóis. In: FAUSTO, B. (Org.). Fazer a América. São Paulo: Edusp, 1999.

MORANDI,A.; ROCHA, H. C. Cafeicultura e grande indústria: a transição no Espírito Santo 1955-1985.Vitória: FCAA, 1991.

MOTA, F. C. M. Integração e dinâmica regional: o caso capixaba (1960-2000). Campinas, 2002. Tese (Doutorado em Economia Aplicada - Universidade Estadual de Campinas).

PORTO, J. L. R. P. Amapá: principais transformações econômicas e institucionais (1943-2000). Campinas, 2002. Tese (Doutorado em Economia Aplicada - Universidade Estadual de Campinas).

PRADO, L.A. Indústria do vestuário e moda no Brasil, séc. XIX a 1960: da cópia e adaptação à autonomização pelo simulacro. São Paulo, 2019. Tese (Doutorado - Universidade de São Paulo).

ROCHA, H. C.; COSSETI, M. da P. Dinâmica cafeeira e constituição da indústria no Espírito Santo (1850-1930).Vitória: UFES/NEP/COPLAN/IJSN/GERES,1983.

SEABRA, O. Os meandros dos rios nos meandros do poder. São Paulo: Alameda, 2019.

SOUZA FILHO, H. M. Modernização violenta: principais transformações na agropecuária capixaba. Campinas, 1990. Dissertação (Mestrado em Economia -Universidade Estadual de Campinas). 